\title{
Friendship Moderates Prospective Associations Between Social Isolation and Adjustment Problems in Young Children
}

\author{
Brett Laursen \\ Florida Atlantic University
}

\author{
William M. Bukowski \\ Concordia University
}

\author{
Kaisa Aunola and Jari-Erik Nurmi \\ University of Jyväskylä
}

\begin{abstract}
This longitudinal study investigated prospective links between social isolation and adjustment problems among 166 (77 girls, 89 boys) Finnish children ages 7 to 9 . Peer nominations for social engagement and self-reports of internalizing and externalizing problems were collected in the spring of the 1st and 2nd grade. Friendship moderated prospective associations between peer and adjustment variables. Among friended children, there were no prospective associations between social isolation and either internalizing or externalizing problems. Among unfriended children, initial social isolation was positively linked to subsequent increases in internalizing and externalizing problems, and initial internalizing and externalizing problems predicted subsequent increases in social isolation. The findings suggest that friendship buffers against the adverse consequences associated with being isolated and presenting adjustment difficulties.
\end{abstract}

Strong evidence implicates peer experiences in individual adjustment. Social isolation and friendlessness have been linked to adverse outcomes beginning in early childhood and running across the life course (Gest, 1997; Hartup \& Stevens, 1997). Most studies of peer influence describe either direct effects, in which individual outcomes are predicted from peer difficulties, or indirect effects, in which associations between peer difficulties and individual outcomes are mediated by friendship quality or quantity (Rubin, Bukowski, \& Parker, 2006). Moderated effects have been largely overlooked. This distinction is important. Direct and mediated effects models start from the premise that the correlates of peer problems are the same for all children; moderated effects models assume that peer problems will be more strongly linked to adjustment problems among children with-

The cooperation of the students, parents, and teachers in the ongoing Jyväskylä Entrance into Primary School (JEPS) project is gratefully acknowledged. This project is funded by grants to Jari-Erik Nurmi from the Academy of Finland (63099 and 778230). Support for the preparation of this manuscript was provided to Brett Laursen by the U.S. National Institute of Mental Health (MH58116). Thanks to Bill Burk and Paloma Prata for their assistance with this article.

Correspondence concerning this article should be addressed to Brett Laursen, Department of Psychology, Florida Atlantic University, 2912 College Avenue, Fort Lauderdale, FL 33314. Electronic mail may be sent to laursen@fau.edu. Correspondence concerning JEPS should be addressed to Jari-Erik Nurmi or Kaisa Aunola, Department of Psychology, University of Jyväskylä, P.O. Box 35, FIN-40014 Jyväskylä, Finland. Electronic mail may be sent to jari-erik.nurmi@psyka.jyu.fi or kaisa.aunola@psyka.jyu.fi. out friends than among children with friends. The present longitudinal study delineates a moderated model of peer influence, testing the hypothesis that friendship is a buffer against adverse consequences associated with social isolation and maladjustment.

We begin with a few definitions. Social engagement describes a child's involvement with peers. To measure social engagement, children nominated classmates with whom they spent the most and the least time. Social participation is an index of inclusion, operationally defined as the number of positive social engagement nominations a child receives. Social isolation is an index of exclusion, operationally defined as the number negative social engagement nominations a child receives. The identification of mutual friends typically involves asking children to name their best or closest friends, but some scholars argue that young children should instead be asked to identify their most frequent playmates (for a review, see Bukowski \& Hoza, 1989). Assessments based on playmate preferences have a long history in the field, dating back to the first sociometric procedures (Renshaw, 1981). Given the central role companionship plays in friendship during early childhood, it is perhaps not surprising that there is a high degree of correspondence between children who claim to spend most of their time together and dyads identified as friends on the basis of teacher ratings (McCandless \&

(C) 2007 by the Society for Research in Child Development, Inc. All rights reserved. 0009-3920/2007/7804-0022 
Marshall, 1957) and observations (Hartup, Laursen, Stewart, \& Eastenson, 1988). In the present study, friendship is indexed by frequent companionship, operationally defined in terms of reciprocal positive social engagement nominations.

Scholars have long recognized the significance of peer influences. Piaget (1932/1965) argued that experiences with peers are an important context for the development of social perspective taking and the acquisition of social skills. Sullivan (1953) suggested that self-concept reflects the degree to which the child is both accepted by the group and successful at establishing and maintaining a close friendship. Contemporary models suggest that peer relationships play a role in the development of internalizing and externalizing problems. One form of peer difficulties, social isolation, is held to be particularly problematic (Rubin, LaMare, \& Lollis, 1990). Inhibited and emotionally insecure children who are isolated from their peers may develop negative appraisals of self-worth and well-being, which are characteristically manifest in depression and anxiety. Hostile children who behave inappropriately are also isolated from their peers, which may prompt increases in aggressive, antisocial behavior. These are not mutually exclusive trajectories; social anxiety and aggression go hand in hand for many who present both internalizing and externalizing problems.

Social isolation has few harmful effects on very young children, but the potential for problems grows as older children increasingly identify it as nonnormative. Several longitudinal studies tie isolation and withdrawal to subsequent internalizing and externalizing problems during primary school. We mention three by way of example. Observed solitary, passive play, and peer-rated isolation/withdrawal during second grade were found to predict teacher-rated anxiety and self-reported depression during fifth grade (Rubin \& Mills, 1998). Children rated by their kindergarten teachers as high on indices of exclusion and anxious solitude demonstrated an increase in teacher ratings of depression from first through fourth grades (Gazelle \& Ladd, 2003). Peer ratings of sensitivity and isolation in a sample of third- through sixth-grade children were found to predict teacher ratings of disruptive, oppositional behavior 1 year later (Masten, Morison, \& Pellegrini, 1985). These and other studies provide strong evidence that individual well-being is closely bound to successful experiences with peers.

Studies of peer influence often reflect an assumption that maladjustment is a product of peer experiences. The direction of the effect, however, is far from certain; it may well be that characteristics of the child determine whether that child is ultimately included in group activities (Newcomb \& Bagwell, 1996). Two longitudinal studies suggest that adjustment problems forecast social isolation. In the first, teacher ratings of internalizing problems during second grade predicted subsequent peer ratings of isolation during fifth grade (Hymel, Rubin, Rowden, \& LaMare, 1990). More recent data indicate that higher levels of internalizing problems in the fourth grade predicted increasing troubles with peer acceptance (a composite variable including exclusion, friendlessness, and unpopularity) in the sixth grade (Flook, Repetti, \& Ullman, 2005). These findings indicate that social isolation is a consequence as well as a cause of childhood adjustment difficulties.

We start from the premise that having a friend is a qualitatively different form of peer experience than not having a friend. Studies that examine direct or mediated effects of friendship obscure this distinction because children with a large number of friends are not necessarily better off than children with one or two friends. The proposition that friendship provides a buffer against both adverse peer experiences and adjustment difficulties is a defining feature of moderated models of peer influence. In this view, friends promote individual well-being and protect young children from the deleterious consequences of social isolation, disrupting the transactional links between peer problems and adjustment problems. Several explanatory mechanisms await empirical confirmation. These proposed mechanisms may be grouped under two broad headings. First, friends may help isolated children avoid internalizing and externalizing problems. The companionship and instrumental support of friends may protect isolated children against feeling lonely, inadequate, and depressed (Parker, Saxon, Asher, \& Kovacs, 1999). Friends may defend isolated children against adversaries, forestalling victimization and the host of adjustment problems that attend it (Bukowski \& Sippola, 2001). During early childhood, friends discourage the norm violations that foreshadow antisocial behavior when left unchecked; isolated children without friends may lack these socialization experiences (Dunn, 2004). Second, friends may help maladjusted children avoid social isolation. The comfort and reassurance of a friend may help reduce the anxiety fueling inappropriate or maladroit behaviors that alienate children from classmates (Erdley, Nangle, Newman, \& Carpenter, 2001). Children with adjustment problems may be included in group activities simply by virtue of friendship with a well-adjusted child (Berndt, 2004). Friends with conventional norms may discourage disruptive displays that tend to get aggressive 
and conduct-disordered children excluded from the peer group (Boivin, Dodge, \& Coie, 1995). In sum, different provisions of friendship may proffer different protective functions.

Speculation about the buffering potential of friendship has far outpaced empirical research on the topic. Most studies have focused on the protection friendship offers against victimization. Links between adjustment problems and bullying/victimization are reliably moderated by the presence of a friend (Hodges, Boivin, Vitaro, \& Bukowski, 1999), the number of friends (Hodges, Malone, \& Perry, 1997), and the quality of the friendship (Bollmer, Milich, Harris, \& Maras, 2005). More relevant to the present inquiry is research on the protection friendship offers against the consequences of social isolation. One study examined peer ratings of social isolation among third- through fifth-grade children and changes in teacher-rated internalizing and externalizing problems 2 years later (Hoza, Molina, Bukowski, \& Sippola, 1995). Initial passive isolation predicted increases in internalizing and initial rejected isolation predicted increases in externalizing. Unexpectedly, friendship participation failed to buffer against the consequences of either form of isolation. The lack of moderated effects may be attributed to the age of the children; by preadolescence, the social landscape has shifted such that well-adjusted peers may no longer befriend isolated children. But this is only speculation. Research has yet to determine whether friendship buffers isolated young children against maladjustment.

The aim of the present study is to explore whether friendship moderates associations between social isolation and adjustment (i.e., internalizing and externalizing problems) during the early grade school years. Children in public schools in Central Finland provided positive and negative social engagement nominations and completed measures of internalizing and externalizing problems during the spring of first grade and during the spring of second grade. We conducted two sets of structural equation models, one with friended first graders and the other with unfriended first graders, to identify differences in patterns of prospective associations among social isolation, social participation, and externalizing problems, and among social isolation, social participation, and internalizing problems. Friendship was expected to moderate patterns of association. For children without friends, we predicted (a) prospective links from social isolation to later internalizing and externalizing problems, and (b) prospective links from internalizing and externalizing problems to later social isolation. Similar patterns were not anticipated for children with friends.

\section{Method}

\section{Participants}

Participants included 166 Finnish children (77 girls, 89 boys) from the Jyväskylä Entrance into Primary School Study (Nurmi \& Aunola, 2000). The present investigation includes data collected in the spring of 2001 when the children were 7 or 8 years old $(M=7.68$, $S D=0.27)$, and data collected in the spring of 2002 when the children were 8 or 9 years old $(M=8.68$, $S D=0.27)$. Participants were drawn from 17 classes in 13 schools in two public school districts in Central Finland. Children in Finland enter primary school in the autumn of the calendar year of their seventh birthday. Of the 219 students enrolled in the first grade, parent permission for participation was obtained from 216. Of this total, 213 children participated in both waves of data collection; data could not be collected from the 3 children whose families left the school district. A total of 47 children in rural mixedgrade classrooms (i.e., Grades 1, 2, and 3 combined) were omitted from the present investigation. Thus, the final sample of 166 participants was drawn from 9 classes that included 10 to 27 students. Participation rates, over time and across classes, ranged from $90.9 \%$ to $100 \%(M=98.1 \%)$. Children kept the same classmates from one year to the next: Only 1 participant changed classes between first and second grades. Twelve new students were enrolled at the start of second grade. These children provided peer nomination data about the 166 target participants but were not otherwise included in the study.

Background information was gathered from the parents of 149 participants (149 mothers, 137 fathers). Of this total, 127 children $(85.2 \%)$ resided in households with two biological parents, 17 (11.4\%) resided in households with one biological parent and one stepparent, and $5(3.4 \%)$ resided in households with single mothers. Of those providing demographic information, 22 (14.8\%) mothers and 21 (15.3\%) fathers reported a university education, 107 (71.8\%) mothers and $100(73.0 \%)$ fathers reported a professional or vocational education, and $20(13.4 \%)$ mothers and $16(11.7 \%)$ fathers reported neither.

\section{Instruments}

Participants completed three identical instruments during the spring semester of the first and second grade. Research assistants administered surveys to participants on an individual basis in a quiet school setting, reading the instructions and each item aloud, and recording the child's response on a questionnaire. 
Adjustment problems. Psychosocial adjustment was assessed in an interview with items adapted from the Johns Hopkins Depression Scale (Joshi, Cappozoli, \& Coyle, 1989) and the Strengths and Difficulties Questionnaire (Goodman, Meltzer, \& Bailey, 1998). Responses were dichotomous: true or not true. Confirmatory factor analysis for categorical items yielded two subscales: Internalizing Problems included five items that described depression and anxiety (e.g., "I am worried about many things"), and Externalizing Problems included four items that described antisocial behavior and interpersonal difficulties (e.g., "I often get into fights"). For each subscale, a summary score of affirmative responses was calculated. Both subscales demonstrated excellent test-retest reliability (range $=.78$ to .82$)$ and split-half (Spearman-Brown) reliability (range $=.64$ to .80 ); internal consistency (Kuder-Richardson 20) was moderate (range $=.62$ to .78). Measurement points with low internal consistency can be attributed in part to the skewed distribution of individual items. Confirmatory factor analyses conducted at each time point indicated that the factor loadings for each of the scales were invariant. Unpublished pilot data revealed statistically significant associations between the scale for externalizing problems and mother ratings of adjustment and between the scale for internalizing problems and teacher ratings of adjustment. Additional details on the construction and validity of these subscales are available elsewhere (Aunola \& Nurmi, 2004, 2005).

Social engagement. A peer-nomination procedure assessed positive and negative dimensions of social engagement. For positive nominations, participants were instructed to identify an unrestricted number of classmates whom "you spend the most time with." For negative nominations, participants were instructed to identify an unrestricted number of classmates whom "you spend the least time with." Cross-sex nominations were permitted, but most children only nominated same-sex peers. Children made more positive nominations (first grade: $M=2.19, S D=1.28$; second grade: $M=2.48, S D=1.21$; range $=0$ to 8$)$ than negative nominations (first grade: $M=0.96, S D=0.91$; second grade: $M=1.09, S D=0.96$; range $=0$ to 5 ).

Mutual friends were identified on the basis of reciprocal positive nominations (first grade: $M=$ $1.18, S D=0.92$; second grade: $M=1.69, S D=1.05$; range $=0$ to 5 ). At total of 122 (66 girls, 56 boys) first-grade participants and 148 (72 girls, 76 boys) second-grade participants were involved in mutual friendships. All but 7 children with a mutual friend in first grade also had a mutual friend in second grade. A greater proportion of girls (85.7\%) than boys $(62.9 \%)$ participated in at least one mutual friendship during first grade, $\chi^{2}(1, N=166)=11.01, p<.01$. There were no statistically significant differences in the proportion of girls $(91.1 \%)$ and boys $(85.4 \%)$ who participated in mutual friendships during second grade.

For each participant, a summary score was calculated reflecting the number of positive nominations received (first grade: $M=2.18, S D=1.58$; second grade: $M=2.48, S D=1.35$; range $=0$ to 8 ) and the number of negative nominations received (first grade: $M=0.89, S D=1.25$; second grade: $M=1.05, S D=$ 1.42 ; range $=0$ to 8 ). Social participation reflects the number of positive nominations received, $z$ score standardized by gender within each class. Social isolation reflects the number of negative nominations received, $z$ score standardized by gender within each class.

\section{Plan of Analysis}

Preliminary analyses identified mean-level differences in social engagement and adjustment problems. Four repeated measures analyses of variance (ANOVAs) were conducted with gender and initial mutual friendship (no friends in first grade and one or more friends in first grade) as between-subject variables. Social isolation, social participation, internalizing problems, and externalizing problems were the dependent measures. Time (Grade 1 and Grade 2) was the repeated measure. These were followed by two sets of correlations to examine patterns of association among social engagement and adjustment problems variables, separately for (a) children with and without friends in first grade and (b) boys and girls. Small samples precluded separate Gender $\times$ Friendship correlational contrasts.

Path analyses conducted with EQS (Bentler, 1995) examined prospective associations among social isolation, social participation, and adjustment problems. Separate models were estimated for internalizing and externalizing problems. The initial models assessed stability over time. These models included three paths: (a) Grade 1 to Grade 2 social participation, (b) Grade 1 to Grade 2 social isolation, and (c) Grade 1 to Grade 2 internalizing or externalizing problems. The parameters of these models were initially constrained to be equal across friendship groups. Chi-square difference statistics guided decisions concerning the retention of specific paths, and model fit indices determined the selection of the best fitting model. A multiple-group procedure identified paths that accounted for inequality between models. Chi-square difference analyses compared final models constrained to be equal across friendship groups to final models 
without constraints. Follow-up chi-square analyses contrasted constrained paths across friendship groups. Patterns of intercorrelations did not differ for boys and girls, a necessary precondition for multiple-group modeling by gender. Small sample sizes precluded the inclusion of gender as a moderator of friendship group differences.

\section{Results}

\section{Preliminary Analyses}

Four repeated measures ANOVAs were conducted to identify differences in social engagement and behavior problems variables as a function of friendship, gender, and time. For externalizing problems, there was a main effect for time, $F(1,144)=4.06$, $p<.05$. Externalizing problems declined from Grade $1(M=0.89, S D=1.16)$ to Grade $2(M=.58, S D=$ 1.10). For internalizing problems, there were no statistically significant differences or two-way interactions. For social participation, there was a two-way interaction between friendship and time, $F(1,162)=$ $15.28, p<.01$. For children who did not have a friend in first grade, social participation increased from Grade $1(M=-0.85, S D=0.62)$ to Grade $2(M=$ $-0.34, S D=0.97)$. For children with at least one friend in first grade, there were no statistically significant differences between social participation in Grade 1 and social participation in Grade 2. For social isolation, there was a main effect for friendship status, $F(1,157)=7.52, p<.01$. In follow-up analyses, Grade 1 and Grade 2 social isolation scores were averaged because there was no effect for time: Social isolation was higher for children who did not have a friend in first grade $(M=0.29, S D=1.06)$ than for children with at least one friend in first grade $(M=-0.11, S D=0.88)$.

Table 1 presents correlations for children with and without friends in first grade. For both friendship groups, positive autocorrelations emerged for social engagement and adjustment problems variables. Grade 1 social participation and Grade 1 social isolation were inversely associated for children without friends but not for children with friends; Grade 1 and Grade 2 social participation were inversely associated with Grade 2 social isolation for children with friends but not for children without friends. For both friendship groups, social participation was unrelated to concurrent and prospective internalizing and externalizing problems. For children without friends, social isolation was positively associated with internalizing and externalizing problems, concurrently (with the exception of Grade 2 social isolation and Grade 2 internalizing problems) and prospectively. For children with friends, social isolation was not linked to internalizing or externalizing problems.

Identical correlational analyses were conducted separately by gender. Correlational contrasts, conducted with Cohen's (1978) partialed products technique, failed to reveal any gender differences in the magnitude of these associations. With one exception, the same statistically significant findings emerged for boys and girls, a pattern that does not differ from that expected by chance.

Concurrent and Prospective Associations Between Social Engagement and Adjustment Problems for Children With and Without Friends in Grade 1

Baseline models were calculated in which all parameters were constrained to be equal for children

Table 1

Intercorrelations Among Social Engagement and Adjustment Problem Variables for Children With and Without Friends in First Grade

\begin{tabular}{|c|c|c|c|c|c|c|c|c|}
\hline Variable & 1 & 2 & 3 & 4 & 5 & 6 & 7 & 8 \\
\hline \multicolumn{9}{|l|}{ First grade } \\
\hline 1. Externalizing problems & - & $.71^{* *}$ & -.04 & .03 & $.31 * *$ & $.25^{* *}$ & -.02 & -.08 \\
\hline 2. Internalizing problems & $.67 * *$ & - & -.06 & .12 & $.21 *$ & $.35^{* *}$ & -.04 & -.14 \\
\hline 3. Social participation & -.10 & -.20 & - & -.14 & .02 & .08 & $.39 * *$ & $-.25^{* *}$ \\
\hline 4. Social isolation & $.46^{* *}$ & $.36^{*}$ & $-.34^{*}$ & - & -.03 & -.14 & -.12 & $.23 *$ \\
\hline \multicolumn{9}{|l|}{ Second grade } \\
\hline 5. Externalizing problems & $.59 * *$ & $.44^{* *}$ & -.18 & $.50 * *$ & - & $.32^{* *}$ & -.04 & .00 \\
\hline 6. Internalizing problems & $.35^{*}$ & $.43^{* *}$ & -.11 & $.53 * *$ & $.45^{* *}$ & - & .05 & -.14 \\
\hline 7. Social participation & .04 & -.14 & $.34^{*}$ & -.24 & -.05 & -.26 & - & $-.31 * *$ \\
\hline 8. Social isolation & $.40 *$ & $.43^{* *}$ & -.22 & $.51^{* *}$ & $.38^{*}$ & .24 & -.15 & - \\
\hline
\end{tabular}

Note. Results for children with friends in first grade (range $=106$ to 122) are given above the diagonal and results for children without friends in first grade (range $=36$ to 44 ) are given below the diagonal.

${ }^{*} p<.05 . * * p<.01$. 
with and without friends. Results indicated that fully constrained models did not provide an adequate fit to the data for internalizing problems, $N=156$, comparative fit index $(\mathrm{CFI})=0.65, \chi^{2}(d f=27)=58.08$, $p<.001$, or externalizing problems, $N=156$, CFI $=$ $0.74, \chi^{2}(d f=27)=47.75, p=.008$. Accordingly, models were respecified to allow path coefficients and covariances among variables to be freely estimated for each friendship group. After determining the best fitting model for each group, paths were again constrained to be equal across groups. The unconstrained model provided a better fit to the data than the constrained model for internalizing problems, $N=156, \chi^{2}$ difference $(d f=2)=16.77, p<.05$, and for externalizing problems, $N=156, \chi^{2}$ difference $(d f=4)=15.92$, $p<.05$.

Internalizing problems. Figure 1 describes the best fitting models for internalizing problems, contrasting children with and without friends in first grade, $N=$ $156, \mathrm{CFI}=1.00, \chi^{2}(d f=12)=3.88, p=.99$. For children with friends in first grade, concurrent associations emerged between social participation and social isolation during Grade 1 and between the residuals of social participation and social isolation during Grade 2 such that greater participation was linked to less

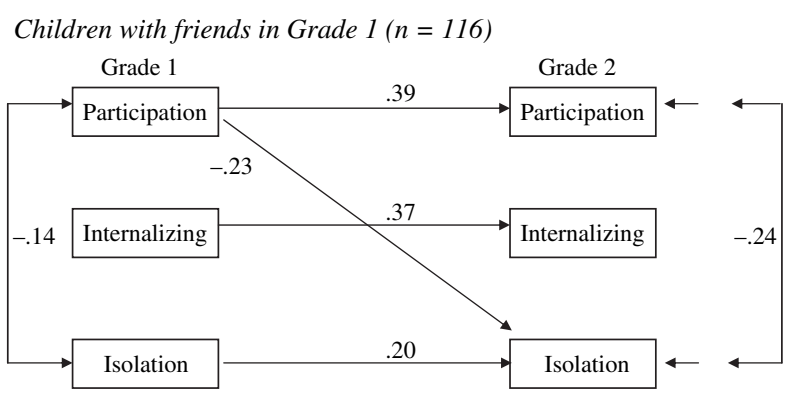

Children without friends in grade $1(n=40)$
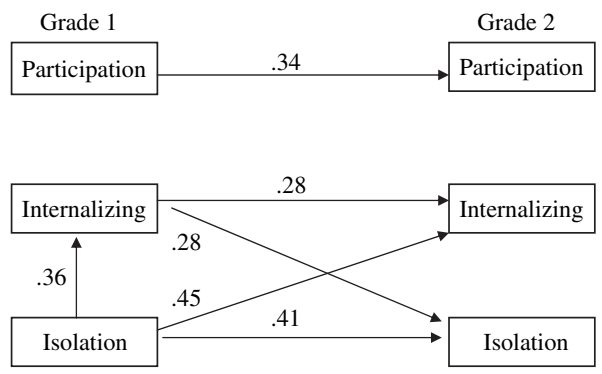

Figure 1. Multiple-group model of concurrent and over-time associations between social participation, social isolation, and internalizing problems among children with and without friends in first grade $(N=156)$. Solid lines represent statistically significant $(p<.05)$ standardized coefficients of association between variables and between the residuals of second grade variables. Nonsignificant paths are omitted. isolation. There were positive over-time associations for social isolation, social participation, and internalizing problems. Grade 1 social participation predicted Grade 2 social isolation; greater initial participation was linked to subsequent decreases in isolation. For children without friends in first grade, concurrent associations emerged between Grade 1 social isolation and Grade 1 internalizing problems such that greater isolation was linked to more internalizing problems. There were positive overtime associations for social isolation, social participation, and internalizing problems. Grade 1 social isolation predicted Grade 2 internalizing problems; greater initial isolation was linked to subsequent increases in internalizing problems. Grade 1 internalizing problems predicted Grade 2 social isolation; more initial internalizing problems were linked to subsequent increases in isolation. Taken together, the findings indicate that positive over-time associations between social isolation and internalizing problems and between internalizing problems and social isolation were limited to children without friends in first grade.

Subsequent analyses contrasted paths constrained to be equal across groups. Statistically significant differences emerged between friended and nonfriended groups for Grade 1 social isolation to Grade 2 internalizing problems, $N=156, \chi^{2}(d f=1)=7.15, p=$ .01; for Grade 1 internalizing problems to Grade 2 social isolation, $N=156, \chi^{2}(d f=1)=3.91, p=.04$; and for Grade 1 social participation and Grade 2 social isolation, $N=156, \chi^{2}(d f=1)=5.46, p=.02$.

Externalizing problems. Figure 2 describes the best fitting models for externalizing problems, contrasting children with and without friends during first grade, $N=156$, CFI $=1.00, \chi^{2}(d f=17)=13.31, p=.72$. For children with friends in first grade, the stability model was the best fitting model: Positive over-time associations emerged for social isolation, social participation, and externalizing problems. For children without friends in first grade, there were positive over-time associations for social isolation, social participation, and externalizing problems. In addition, Grade 1 social isolation predicted Grade 2 externalizing problems; greater initial isolation was linked to subsequent increases in externalizing problems. Grade 1 externalizing problems predicted Grade 2 social isolation; more initial externalizing problems were linked to subsequent increases in isolation. Taken together, the findings indicate that positive over-time associations between social isolation and externalizing problems and between externalizing problems and social isolation were limited to firstgrade children without friends. 
Children with friends in Grade $1(n=116)$

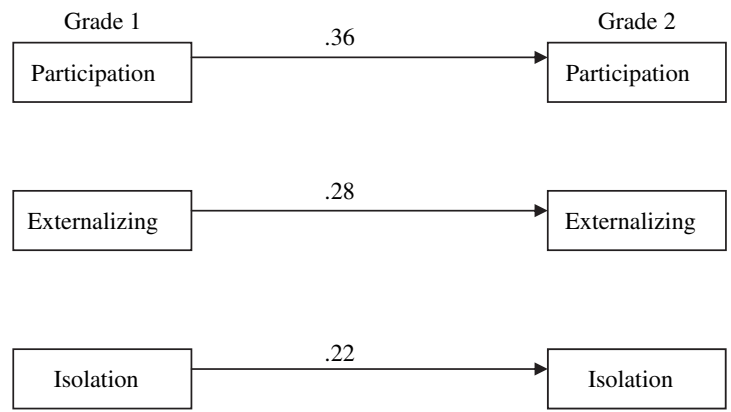

Children without friends in Grade $(n=40)$

\begin{tabular}{|c|c|c|}
\hline Grade 1 & & Grade 2 \\
\hline Participation & .29 & Participation \\
\hline
\end{tabular}

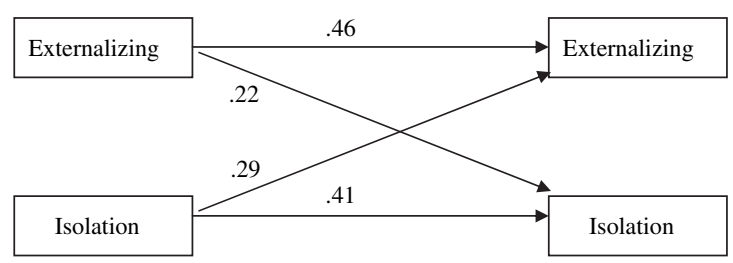

Figure 2. Multiple-group model of concurrent and over-time associations between social participation, social isolation, and externalizing problems among children with and without friends in first grade $(N=156)$. Solid lines represent statistically significant $(p<.05)$ standardized coefficients of association between variables. Nonsignificant paths are omitted.

Subsequent analyses contrasted paths constrained to be equal across groups. Statistically significant differences emerged between friended and nonfriended groups for Grade 1 social isolation to Grade 2 externalizing problems, $N=156, \chi^{2}(d f=1)=3.56, p=$ .05 , and for Grade 1 externalizing problems to Grade 2 social isolation, $N=156, \chi^{2}(d f=1)=9.86, p=.002$.

\section{Discussion}

This study was designed to test the hypothesis that friendship buffers against the adverse consequences associated with social isolation and adjustment problems. The results indicate that friendship moderates the interplay between peer and adjustment difficulties. Among children without friends, higher levels of social isolation during first grade predicted subsequent increases in internalizing and externalizing problems during second grade, and higher levels of internalizing and externalizing problems during first grade predicted subsequent increases in social isolation during second grade. Among children with friends, there were no prospective links between social isolation and either internalizing or externalizing problems. These findings support claims that friends may protect children against the debilitating cycle of isolation and maladjustment.

It is important to note that the present study was not designed to shed light on the precursors of peer troubles. Ladd and colleagues (e.g., Ladd \& TroopGordon, 2003) have convincingly demonstrated that most middle-childhood peer difficulties have origins in early childhood aggression and anxiety. We should also note that the present study does not address the consequences of chronic peer rejection. The prognosis for children in this extreme group is notoriously poor (Parker, Rubin, Price, \& DeRosier, 1995). The present study is unique, however, in its depiction of transactions between social isolation and adjustment problems. We are not the first to suggest that peer difficulties and adjustment problems feed off each other, but we are the first to show that some of these transactional processes may be specific to young children without friends.

How might friends buffer against the downward spiral of social isolation and maladjustment? We can only speculate on potential protective mechanisms. The provision of instrumental support is one likely avenue. Children with friends are less likely to be victimized than children without friends, and having a friend attenuates problems that might otherwise be associated with victimization (Hodges et al., 1999). Friends may also provide an opportunity for anxious children to enrich their impoverished social skills and ward off future isolation. Socially withdrawn children participating in dyadic play sessions designed to encourage social interaction subsequently increased positive behaviors directed toward peers (Furman, Rahe, \& Hartup, 1979). A close friend may also provide an unpopular child with an entree into the social world of accepted and well-adjusted agemates. Friends help isolated children make positive contacts that enhance the child's position in the peer group, which in turn may reduce distress arising from peer difficulties and provide a constructive model for nondeviant behavior (Berndt, 2004). Finally, friendships may spur social cognitive development among children who lack mature concepts of social exchange. Through experiences with friends, children abandon their exclusive focus on personal gains in peer interactions in favor of behaviors that promote mutual gain, a transformation that bolsters friendship bonds, enhances self-worth, and decreases the likelihood 
that the individual will be excluded from group activities (Laursen \& Hartup, 2002).

Of course, friendship is not a panacea. Some isolated youth with severe difficulties may be beyond the help of friends. Then too, friends may only buffer against the debilitating effects of maladjustment if they do not suffer from a similar liability. Studies of older children indicate that troubled youth with friends fare worse over time than those who lack friends (Kupersmidt, Burchinal, \& Patterson, 1995), associations readily explained by the fact that antisocial friends tend to encourage and elicit deviant behavior (Brendgen, Vitaro, \& Bukowski, 2000; Dishion, Andrews, \& Crosby, 1995).

Two points should be mentioned with regard to the present study. First, our study differed from others, including a previous investigation that failed to find evidence that friendship moderated associations between social isolation and later adjustment problems (Hoza et al., 1995), in that we tracked participants from the beginning of their academic career. It seems likely that peer networks during the first years of formal schooling have not hardened to the point where troubled children have only each other as playmates. These claims are bolstered by supplemental analyses indicating that there were no statistically significant resemblances between friends on social engagement or adjustment problems variables. Second, our study did not distinguish those with fleeting friendships from those with stable friendships nor from those who are chronically friendless; neither did it separate the majority of children with highquality relationships from the minority with lowquality relationships. Buffering capabilities are likely to be influenced by the stability and quality of the friendship and the relative proportion of time that a child is friended.

Social participation was unrelated to adjustment problems among friended and unfriended children alike. This finding is the second to indicate that positive peer nominations do not make an independent contribution to the prediction of individual adjustment. In a prior study of primary school children, acceptance and rejection were both correlated with peer nomination scores for aggressive/disruptive, sociability/leadership, and sensitivity/isolation, but regression analyses ascribed unique variance to rejection only (Gest, Graham-Bermann, \& Hartup, 2001). Taken together, these findings have important implications for the prediction of maladjustment. Scholars are urged to maintain a clear distinction between social preference scores and positive and negative nomination scores: Negative nominations may be stronger markers of maladjustment than positive nominations because the latter contains variance attributed to social preferences that tend not to be uniquely related to the prediction of adjustment problems.

No study is without limitations. Broadly speaking, research on peer influences has been criticized for overestimating the magnitude of effects attributed to agemates (Jaccard, Blanton, \& Dodge, 2005). Peer relations are embedded in a constellation of factors that shape interpersonal and individual functioning. Expanding the scope of inquiry will most certainly reveal a complex dynamic between parent and peer influences, as suggested by research indicating that social preference and friendship moderate links between family adversity and subsequent externalizing behaviors (Criss, Pettit, Bates, Dodge, \& Lapp, 2002). This investigation involved a relatively small, homogeneous group of children living in the very north of Europe. Generalizability is an appropriate concern. It will fall to future investigators to determine whether a larger group of children living in other settings have peers who are similarly influential. Boys were overrepresented among friendless children; findings for girls should be interpreted with caution.

These concerns should be balanced against factors that may contribute to an underestimation of peer influences in the present study. First, our inquiry involved reciprocal nominations of frequent companions, not friends. Previous studies (e.g., Hartup et al., 1988; McCandless \& Marshall, 1957) indicate that this metric compares favorably with more direct measures of friendship but we do not rule out the possibility that some children may have been misclassified, increasing error variance and reducing the magnitude of differences between children with and without friends. On a related note, the fact that mutual friendships were derived from the same reports as social participation may have increased their shared variance and reduced the chances of detecting a statistically significant interaction between these variables. Second, our model assumed that all friends were developmental assets. A more accurate model would distinguish beneficial from detrimental friendships, delineating characteristics of each that amplify and reduce risks. Third, the nomination procedure did not permit us to make distinctions between passiveanxious isolation and active-immature isolation (Rubin \& Mills, 1988). Better measures of isolation will paint a more accurate picture of the links between different forms of isolation and different types of maladjustment. Longitudinal data tracking both forms of isolation are needed to reconcile results from the present inquiry with findings indicating that 
neither form is related to maladjustment during middle childhood (Hoza et al., 1995). Fourth, our models were unable to determine whether there were nonlinear associations between social engagement and adjustment problem variables. Mean-level differences between friended and friendless children raise the possibility that associations involving social isolation may be strongest among those who have the most difficulties with peers. Similarly, associations involving social participation may have been suppressed by the fact that friendless children received few, if any, positive nominations. Finally, child reports of adjustment problems were stable but they demonstrated less than perfect reliability. Decreasing the variance attributed to error would strengthen findings by increasing the variance that may be ascribed to peer influences.

The results suggest that friends may play a critical role in determining the success of interventions designed to improve peer relations. Much is known about the efficacy of programs designed to improve children's social skills (Bierman, 2003); little is known about whether they facilitate the development of friendships that buffer against maladjustment (Rubin et al., 2006). Our findings suggest that friendship may prevent or arrest transactions between social isolation and adjustment problems, but they leave open questions concerning which features of friendship buffer against adverse outcomes and whether a good friend can rehabilitate a maladjusted child. We know that friends are important to children and that most children appreciate the significance of having a friend. Our task is to understand better how friends contribute to adaptive and maladaptive outcomes.

\section{References}

Aunola, K., \& Nurmi, J.-E. (2004). Maternal affection moderates the impact of psychological control on a child's mathematical performance. Developmental Psychology, 40, 965-978.

Aunola, K., \& Nurmi, J.-E. (2005). The role of parenting styles in children's problem behavior. Child Development, 76, 1144-1159.

Bentler, P. M. (1995). EQS structural equations program manual. Encino, CA: Multivariate Software.

Berndt, T. J. (2004). Children's friendships: Shifts over a half-century in perspectives on their development and their effects. Merrill-Palmer Quarterly, 50, 206-223.

Bierman, K. L. (2003). Peer rejection: Developmental processes and interventions. New York: Guilford.

Boivin, M., Dodge, K. A., \& Coie, J. D. (1995). Individualgroup behavioral similarity and peer status in experimental play groups of boys: The social misfit revisited. Journal of Personality and Social Psychology, 69, 1107-1129.
Bollmer, J. M., Milich, R., Harris, M. J., \& Maras, M. A. (2005). A friend in need: The role of friendship quality as a protective factor in peer victimization and bullying. Journal of Interpersonal Violence, 20, 701-712.

Brendgen, M., Vitaro, F., \& Bukowski, W. M. (2000). Deviant friends and early adolescents' emotional and behavioral adjustment. Journal of Research on Adolescence, 10, $173-189$.

Bukowski, W. M., \& Hoza, B. (1989). Popularity and friendship: Issues in theory, measurement, and outcomes. In T. J. Berndt \& G. W. Ladd (Eds.), Peer relations in child development (pp. 15-45). New York: Wiley.

Bukowski, W. M., \& Sippola, L. (2001). Groups, individuals, and victimization: A view of the peer system. In J. Juvonen \& S. Graham (Eds.), Peer harassment in school: The plight of the vulnerable and victimized (pp. 355-377). New York: Guilford.

Cohen, J. (1978). Partialed products are interactions: Partialed powers are curve components. Psychological Bulletin, 85, 858-866.

Criss, M. M., Pettit, G. S., Bates, J. E., Dodge, K. A., \& Lapp, A. L. (2002). Family adversity, positive peer relationships, and children's externalizing behavior: A longitudinal perspective on risk and resilience. Child Development, 73, 1220-1237.

Dishion, T. J., Andrews, D. W., \& Crosby, L. (1995). Antisocial boys and their friends in early adolescence: Relationship characteristics, quality, and interactional process. Child Development, 66, 139-151.

Dunn, J. (2004). Children's friendships: The beginnings of intimacy. Oxford, UK: Blackwell.

Erdley, C. A., Nangle, D. W., Newman, J. E., \& Carpenter, E. M. (2001). Children's friendship experiences and psychological adjustment: Theory and research. In D. W. Nangle \& C. A. Erdley (Eds.), The role of friendship in psychological adjustment. New Directions for Child and Adolescent Development, 91 (pp. 5-24). San Francisco: Jossey-Bass.

Flook, L., Repetti, R. L., \& Ullman, J. B. (2005). Classroom social experiences as predictors of academic performance. Developmental Psychology, 41, 319-327.

Furman, W., Rahe, D. F., \& Hartup, W. W. (1979). Rehabilitation of socially withdrawn preschool children through mixed-age and same-age socialization. Child Development, 50, 915-922.

Gazelle, H., \& Ladd, G. W. (2003). Anxious solitude and peer exclusion: A diathesis-stress model of internalizing trajectories in childhood. Child Development, 74, 257-278.

Gest, S. D. (1997). Behavioral inhibition: Stability and association with adaptation from childhood to early adulthood. Journal of Personality and Social Psychology, 72, 467-475.

Gest, S. D., Graham-Bermann, S. A., \& Hartup, W. W. (2001). Peer experience: Common and unique features of number of friendships, social network centrality, and sociometric status. Social Development, 10, 24-40.

Goodman, R., Meltzer, H., \& Bailey, V. (1998). The Strengths and Difficulties Questionnaire: A pilot study on the validity of the self-report version. European Child and Adolescent Psychiatry, 7, 125-130. 
Hartup, W. W., Laursen, B., Stewart, M. I., \& Eastenson, A. (1988). Conflict and the friendship relations of young children. Child Development, 59, 1590-1600.

Hartup, W. W., \& Stevens, N. (1997). Friendships and adaptation in the life course. Psychological Bulletin, 121, 355-370.

Hodges, E. V. E., Boivin, M., Vitaro, F., \& Bukowski, W. M. (1999). The power of friendship: Protection against an escalating cycle of peer victimization. Developmental Psychology, 35, 94-101.

Hodges, E. V. E., Malone, M. J., \& Perry, D. G. (1997). Individual risk and social risk as interacting determinants of victimization in the peer group. Developmental Psychology, 33, 1032-1039.

Hoza, B., Molina, B., Bukowski, W. M., \& Sippola, L. K. (1995). Peer variables as predictors of later childhood adjustment. Development and Psychopathology, 7, $787-802$.

Hymel, S., Rubin, K. H., Rowden, L., \& LaMare, L. (1990). Children's peer relationships: Longitudinal prediction of internalizing and externalizing problems from middle to late childhood. Child Development, 61, 2004-2021.

Jaccard, J., Blanton, H., \& Dodge, T. (2005). Peer influences on risk behavior: An analysis of the effects of a close friend. Developmental Psychology, 41, 135-147.

Joshi, P., Cappozoli, J., \& Coyle, J. (1989). The Johns Hopkins Depression Scale: Normative data and validation in child psychiatry patients. Journal of American Academy of Child and Adolescent Psychiatry, 29, 283-288.

Kupersmidt, J. B., Burchinal, M., \& Patterson, C. J. (1995). Developmental patterns of childhood peer relations as predictors of externalizing behavior problems. Development and Psychopathology, 7, 649-668.

Ladd, G. W., \& Troop-Gordon, W. (2003). The role of chronic peer difficulties in the development of children's psychological adjustment problems. Child Development, 74, 1344-1367.

Laursen, B., \& Hartup, W. W. (2002). The origins of reciprocity and social exchange in friendships. In B. Laursen \& W. G. Graziano (Eds.), Social exchange in development. New Directions for Child and Adolescent Development (No. 95, pp. 27-40). San Francisco: Jossey-Bass.

Masten, A. S., Morison, P., \& Pellegrini, D. S. (1985). A revised class play method of peer assessment. Developmental Psychology, 21, 523-533.
McCandless, B. R., \& Marshall, H. R. (1957). A picture sociometric technique for preschool children and its relation to teacher judgments of friendship. Child Development, 28, 139-147.

Newcomb, A. F., \& Bagwell, C. L. (1996). The developmental significance of friendship relations. In W. M. Bukowski, A. F. Newcomb, \& W. W. Hartup (Eds.), The company they keep: Friendship in childhood and adolescence (pp. 289-321). New York: Cambridge University Press.

Nurmi, J.-E., \& Aunola, K. (2000). The Jyväskylä Entrance into Primary School study. University of Jyväskylä, Finland.

Parker, J. G., Rubin, K. H., Price, J. M., \& DeRosier, M. E. (1995). Peer relationships, child development, and adjustment: A developmental psychopathology perspective. In D. Cicchetti \& D. J. Cohen (Eds.), Developmental psychopathology: Vol. 2. Risk, disorder, and adaptation (pp. 96-161). New York: Wiley.

Parker, J. G., Saxon, J. L., Asher, S. R., \& Kovacs, D. M. (1999). Dimensions of children's friendship adjustment: Implications for understanding loneliness. In K. J. Rotenberg \& S. Hymel (Eds.), Loneliness in childhood and adolescence (pp. 201-221). New York: Cambridge University Press.

Piaget, J. (1965). The moral judgment of the child. New York: Free Press. (Original work published 1932)

Renshaw, P. D. (1981). The roots of current peer interaction research: A historical analysis of the 1920s. In S. R. Asher \& J. M. Gottman (Eds.), The development of children's friendships (pp. 1-25). New York: Cambridge University Press.

Rubin, K. H., Bukowski, W. M., \& Parker, J. G. (2006). Peer interactions, relationships, and groups. In W. Damon \& R.M. Lerner (Series Eds.) and N. Eisenberg (Vol. Ed.), The handbook of child psychology: Vol. 3. Social, emotional, and personality development (6th ed., pp. 571-645). New York: Wiley.

Rubin, K. H., LaMare, L. J., \& Lollis, S. (1990). Social withdrawal in childhood: Developmental pathways to peer rejection. In S. R. Asher \& J. D. Coie (Eds.), Peer rejection in childhood (pp. 217-249). New York: Cambridge University Press.

Rubin, K. H., \& Mills, R. S. L. (1988). The many faces of social isolation in childhood. Journal of Consulting and Clinical Psychology, 56, 916-924.

Sullivan, H. S. (1953). The interpersonal theory of psychiatry. New York: Norton. 